\title{
Evidence of natural interspecific recombinant viruses between bovine alphaherpesviruses 1 and 5
}

\author{
Silvina Soledad Maidana ${ }^{\mathrm{a}, \mathrm{b}, \mathrm{c}, *}$, Patricio Oliver Craig ${ }^{\mathrm{d}}$, María Isabel Craig ${ }^{\mathrm{a}}$, Louisa Ludwig ${ }^{\mathrm{e}}$, \\ Axel Mauroye, Etienne Thiry ${ }^{\mathrm{e}}$, Sonia Alejandra Romera ${ }^{\mathrm{a}, \mathrm{b}, \mathrm{c}, \mathrm{f}}$ \\ ${ }^{a}$ Instituto de Virología, Centro de Investigaciones en Ciencias Veterinarias y Agronómicas (CICVyA), Instituto de tecnología Agropecuaria (INTA), N. Repetto y Los Reseros \\ S/N, CC25, B1712WAA, Castelar, Buenos Aires, Argentina \\ b Consejo Nacional de Investigaciones Científicas y Tecnológicas (CONICET), Rivadavia 1917 (C1033AAJ), Ciudad Autónoma de Buenos Aires, Argentina \\ c Cátedra de Inmunogenética, Facultad de Ciencias exactas, Químicas y Naturales, Universidad de Morón, Cabildo 134 (B1708JPD) Morón, Buenos Aires, Argentina \\ d Instituto de Química Biológica de la Facultad de Ciencias Exactas y Naturales (IQUIBICEN-UBA/CONICET) y Departamento de Química Biológica, FCEN, UBA, \\ Argentina \\ e Veterinary Virology and Animal Viral Diseases, Fundamental and Applied Research on Animal Health center and Faculty of Veterinary Medicine, University of Liège, \\ Boulevard de Colonster, 20, B43b, B-4000 Liège, Belgium \\ ${ }^{\mathrm{f}}$ Cátedra de Inmunología, Universidad del Salvador, Champagnat 1599, Ruta Panamericana, Km 54.5 Pilar, B1630AHU, Provincia de Buenos Aires, Argentina
}

\section{A R T I C L E I N F O}

\section{Keywords:}

Alphaherpesviruses

Bovine herpesvirus 1 (BoHV-1)

Bovine herpesvirus 5 (BoHV-5)

Natural recombination

Glycoprotein B

\begin{abstract}
A B S T R A C T
Closely related bovine alphaherpesviruses 1 (BoHV-1) and 5 (BoHV-5) co-circulate in certain countries, rendering cattle co-infection possible. This is a prerequisite for BoHV recombination. Here, we report the first identification of homologous recombination between field isolates of BoHV-1 and BoHV-5, two alphaherpesviruses belonging to two distinct species with an average genomic similarity of $82.3 \%$. Three isolates of BoHV-5, previously classified as subtype "BoHV-5b", were phylogenetically studied and analyzed via eight PCR sequencing assays dispersed at regular intervals throughout the genome to discriminate between BoHV-1 and BoHV-5. In the phylogenetic analysis, differences of clustering were found in the UL27 gene which encodes the glycoprotein B (gB). We detected two recombination breakpoints in the open reading frame of the UL27 gene. We compared the amino acid sequences of the $\mathrm{gB}$ of BoHV-1.1 and 1.2, BoHV-5a and recombinant formerly named BoHV-5b (chimeric gB) and subsequently performed molecular modeling. All structures were alike and, simultaneously, similar to the chimeric gB. Neutralizing antibodies against BoHV-1, BoHV-5 and recombinant viruses were analyzed via serum virus neutralization test using polyclonal sera and a monoclonal antibody against $\mathrm{gB}$ to demonstrate an absence of viral escape for both assays.

Our results show that homologous recombination between two related species of ruminant alphaherpesviruses can occur in natural field conditions. We found three recombinant field isolates, previously classified as BoHV-5b subtypes, between BoHV-1 and BoHV-5.
\end{abstract}

\section{Introduction}

Within the Herpesviridae family, Alphaherpesvirinae is an extensive subfamily containing numerous viruses of great relevance for both human and animal health and associated economic production. As regards the latter, bovine herpesvirus 1 (BoHV-1) is the etiological agent of infectious bovine rhinotracheitis, infectious pustular vulvo-vaginitis, abortion and balanoposthitis, and it also is an important component of the bovine respiratory disease complex, causes severe economic losses and imposes restrictions to international livestock trade. Endemic in cattle populations worldwide (Raaperi et al., 2014), BoHV-1 co- circulates with the closely related bovine herpesvirus 5 (BoHV-5) rarely in Europe, Australia and the USA but with a strong geographical distribution in South America (Del Medico Zajac et al., 2010).

Nucleotide substitution rates are low in alphaherpesviruses, estimated to lie at around $3 \times 10^{-8}$ per site per year (Sakaoka et al., 1994). The overall rate of herpesvirus protein sequence evolution has been estimated at $3 \times 10^{-9}$ per amino acid per year (McGeoch et al., 2000). This is an order of magnitude greater than the evolutionary rate of mammalian nuclear genes (Shackelton and Holmes, 2004), suggesting that alphaherpesviruses may evolve faster than their hosts. However, the mutation rate is still low as compared to that of other

\footnotetext{
* Corresponding author at: Instituto de Virología, Centro de Investigaciones en Ciencias Veterinarias y Agronómicas (CICVyA), Instituto de tecnología Agropecuaria (INTA), N. Repetto y Los Reseros S/N, CC25, B1712WAA, Castelar, Buenos Aires, Argentina.

E-mail address: maidana.silvina@inta.gob.ar (S.S. Maidana).
} 
viruses (e.g. RNA viruses), indicating that additional mechanisms must act together with mutations to mediate herpesvirus evolution (Schynts et al., 2003). Of these mechanisms, homologous recombination is the most frequent in herpesviruses, although illegitimate recombination has also been observed (Rijsewijk et al., 1999; Umene, 1999). Whether viral recombination in general is driven by mechanistic constraints associated with genome structures or is selectively favoured as a means to increase genetic diversity end eliminate deleterious mutations, it is undisputed that recombination can be considered as an essential driving force to increase the occurrence of rare but advantageous mutations within a viral species (Thiry et al., 2006). Highlighting the importance of recombination during herpesvirus history, sequence analysis has shown strong evidence of past natural homologous recombination events in several species, including human (Loncoman et al., 2017; Norberg et al., 2007, 2006, 2004; Peters et al., 2006) and animal (Hughes and Rivailler, 2007; Lee et al., 2011, 2015; Pagamjav et al., 2005) alphaherpesviruses.

In vitro and in vivo, herpesvirus recombination has been studied between distinguishable strains of herpes simplex virus 1 or 2 (HSV-1 and HSV-2) (Brown et al., 1992; Nishiyama et al., 1991), varicellazoster virus (VZV) (Dohner et al., 1988), pseudorabies virus (PRV) (Dangler et al., 1993; Glazenburg et al., 1994; Henderson et al., 1990), feline herpesvirus 1 (FeHV1) (Fujita et al., 1998) and BoHV-1/5 (Del Medico Zajac et al., 2010; Meurens et al., 2004; Schynts et al., 2003; Schynts et al., 2001). Interspecies recombinants between BoHV-1 and BoHV-5, at a reduced degree of average similarity (82.3\%), were obtained under in vitro co-infection by Meurens et al. (2004). More recently, these recombinants were characterized regarding both their genome structure and their virulence in natural hosts (Del Medico Zajac et al., 2011, 2009) and showed attenuated replication characteristics and established latency in the natural host.

While natural homologous recombination has been described in different species of alphaherpesviruses, it occurs most commonly as intraspecies recombination. Interspecies recombination however appears to be rare with a single reported detection between equine herpesviruses 1 and 4 in field samples (Pagamjav et al., 2005). It has not yet been reported between human alphaherpesviruses or other animal alphaherpesviruses.

The examination of natural intra- and interspecies recombination of bovine herpesviruses is especially relevant with respect to the widespread use of attenuated BoHV-1 vaccines (Muylkens et al., 2006; van Drunen Littel-van den Hurk, 2007) and risks to animal health posed by the potential of recombination between bovine herpesviruses and live attenuated vaccine strains. While live attenuated vaccines against BoHV-1 are not used in Argentina, the co-circulation of BoHV-1 and BoHV-5 presents a unique opportunity for co-infection and subsequent recombination between strains.

In this work, we a report the first molecular detection of interspecies recombinant field isolates between two alphaherpesviruses BoHV-1 and BoHV-5, previously isolated in Argentina and known as BoHV-5 subtype b (Maidana et al., 2013).

\section{Materials and methods}

\subsection{Virus population samples and cell culture}

Viruses used in this study were propagated in Madin Darby bovine kidney (MDBK) cells and viral stocks were produced after infection of MDBK cells at a multiplicity of infection (MOI) of 0.01 , as previously described (Romera et al., 2000) (Table 1). MDBK monolayers were grown in 12-well plates, and infected with 1:10 serial dilutions of the isolates A663, 166/84 (Maidana et al., 2011) and 674/10 (Maidana et al., 2013). After incubation for $2 \mathrm{~h}$ at $37^{\circ} \mathrm{C}$, viral inocula were removed by washing. To detect the progeny generated specifically by each viral particle, $2 \mathrm{ml}$ carboxymethyl cellulose (CMC)/FBS (7,5 g/L CMC, 480 ml/L MEM-D 2X, 20 ml/L SFB) semisolid overlay were added
Table 1

Bovine herpesvirus isolates and reference strain used in this study.

\begin{tabular}{llll}
\hline Viruses & Strain & Subtype & Reference \\
\hline BoHV1 & Cooper & 1.1 & d'Offay et al. (1993) \\
& K22 & $1.2 \mathrm{~b}$ & \\
& $688 / 10^{\mathrm{a}}$ & $1.2 \mathrm{~b}$ & \\
BoHV5 & SV507/99 & $\mathrm{a}$ & Delhon et al. (2003) \\
& $06 / 13^{\mathrm{a}}$ & $\mathrm{a}$ & \\
& $\mathrm{A} 663$ & $\mathrm{~b}$ & Carrillo BJ et al. (1983) \\
& $166 / 84$ & $\mathrm{~b}$ & Maidana et al. (2011) \\
& $674 / 10$ & $\mathrm{~b}$ & \\
\hline
\end{tabular}

${ }^{\text {a }}$ Field isolates with low passage number used in in vitro assays.

to each well. Plates were incubated for $72 \mathrm{~h}$ at $37^{\circ} \mathrm{C}$. Finally, several $(\mathrm{n}=30)$ isolated lysis plaques were selected and replicated individually to isolate and amplify a single viral clone.

\subsection{PCR, DNA sequence and phylogenetic studies}

Eight different sets of primers, spread along the genome were used in this study. They served to amplify regions located in the unique long (UL) region (UL41, UL40, UL29, UL28, UL27 and UL22) (Del Medico Zajac et al., 2009; Maidana et al., 2011) and the short (US) region (US6 and US8) as previously described by (Thiry et al., 2007) (Table 1). Nucleotide sequences of the isolates were edited and analyzed with BioEdit version 7.0.5.3 (Hall et al., 1999). Alignments were performed with Clustal W. MEGA 5.0 software (Tamura et al., 2011). A phylogenetic inference was performed using the MEGA version 5 software package based on UL27 and US6, which are conventionally used to study the phylogenetic relationships amongst ruminant alphaherpesviruses. Tree topology was constructed via maximum composite likelihood method with the Tamura and Nei model (1000 replicate bootstrap values).

\subsection{Recombination analysis}

The complete UL27 gene of the three BoHV5b isolates, responsible for the differential clustering in the phylogenetic analysis, was amplified by PCR and sequenced. Subsequently, genetic recombination was analyzed using a sliding-window genetic diversity plot (Simplot software version 3.5 .1 available at http://sray.med.som.jhmi.edu/ SCRoftware) (Lole et al., 1999) and the Recombinant Detection Program (RDP) (Martin et al., 2015), version 3, available at http:// darwin.uvigo.es/rdp/rdp.html.

\subsection{Amino acid sequence comparison}

Amino acid (aa) sequences for the entire gB were compared between the BoHVs. Alignments and sequence identity matrices were performed with Clustal W. MEGA 5.0 software (Tamura et al., 2011). To evaluate potential antigenicity changes in $\mathrm{gB}$ due to limited aa sequence variations in BoHV1.2b, BoHV5a and BoHV5b isolates, we performed epitope predictions of these sequences using BepiPred (http://www.iedb. org/). This program predicts the location of linear B-cell epitopes using a combination of a hidden Markov model and surface propensity scale method. The residues with scores above the threshold (1.5) are predicted to be part of an epitope. The number of epitopes predicted in recombinant $\mathrm{gB}$ was compared to that of the parental viruses.

\subsection{Molecular modeling}

Structural models of gB from BoHV-1.2b, BoHV-5 and field isolates were constructed with the program SWISS-MODEL (http://swissmodel. expasy.org/; (Guex and Peitsch, 1997; Kiefer et al., 2009; Schwede et al., 2003), using the HSV-1 gB crystal structure 3NW8 as template 


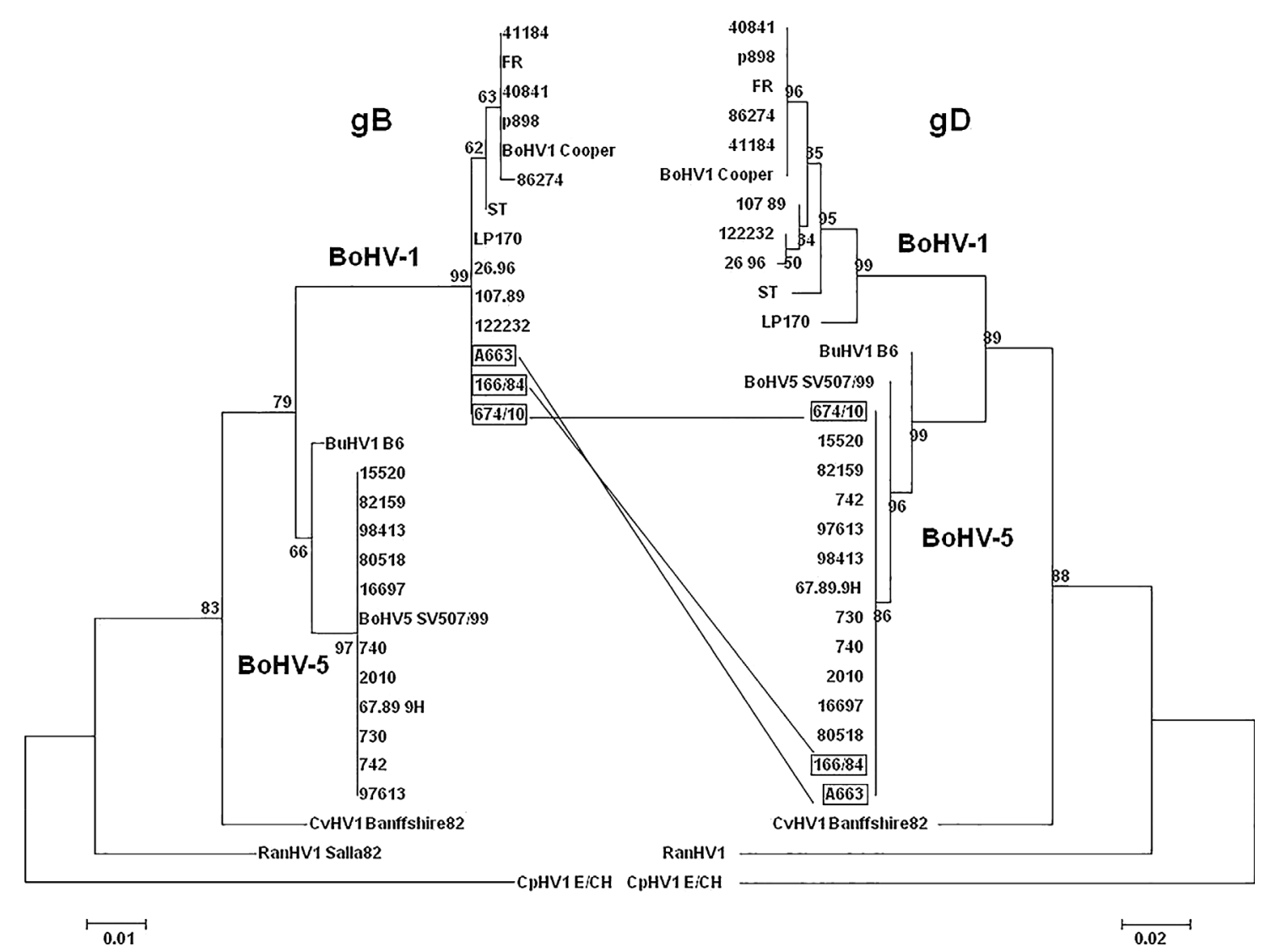

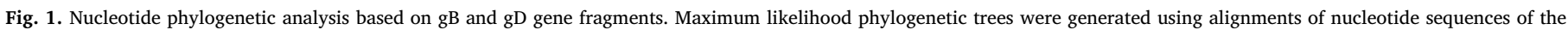

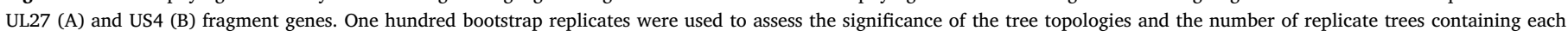

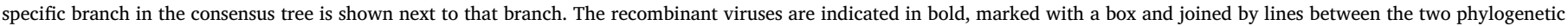
trees showing different clustering with BoHV-1 or BoHV5 depending on the analyzed gene.

(Stampfer et al., 2010). Overall composite quality scores (Benkert et al., 2011) and estimated residue errors were evaluated. The models obtained were compared to each other, and also to the HSV-1 gB crystal structure 3NW8 (Stampfer et al., 2010), accessed via the Research Collaboratory for Structural Bioinformatics protein databank (RCSB PDB) (http://www.pdb.org; Berman et al., 2000) (Heldwein et al., 2006).

\subsection{Lysis and infection plaque size assays}

MDBK monolayers grown in 6 wells culture plates were inoculated with the recombinant isolates (A663, 166/84 and 674/10) and the possible parental viruses (BoHV1.2b and BoHV5a) at tenfold serial dilutions. The viruses used in these tests had a low number of passages in cell culture; to maintain this condition were used as parental strains field isolates previously characterized by molecular biology (688/ $10=$ BoHV1.2b, 06/13 = BoHV5a). After $2 \mathrm{~h}$ of incubation at $37^{\circ} \mathrm{C}$, the inoculum was removed and $2 \mathrm{ml}$ of carboxy methyl cellulose (CMC) $1.5 \%$ FCS per well were added. Plates were incubated at $37^{\circ} \mathrm{C}$ for $72 \mathrm{~h}$. For the lysis plaque size assay, cells were fixed with $10 \%$ formaldehyde for $10 \mathrm{~min}$ at room temperature, stained with violet crystal (1\% violet crystal, $10 \%$ ethanol in PBS) for 20 min and washed in PBS. For each virus, 30 isolated and randomly selected lysis plaques were observed with an optical microscope and photographed. For the infection plaque size assay, cells were fixed with 4\% paraformaldehyde (PFA) for $10 \mathrm{~min}$ at room temperature. After washing in PBS, cells were incubated for $1 \mathrm{~h}$ at $37^{\circ} \mathrm{C}$ with an anti IBR-FIT-C conjugated antibody (USBilogical life sciences, U.S.A) diluted in PBS and then cells were washed twice in PBS. For each virus, 20 isolated and randomly selected infectious foci were observed with a fluorescent microscope and photographed. The photographs were analyzed with ImageJ software in order to calculate lysis and infection plaques surfaces. For both assay statistical analysis was performed using one way ANOVA and the Tukey test.

\subsection{Serum neutralization assay ( $S N)$ and virus neutralization (VN) assays}

To study the rate of neutralization, we performed a serum-virus neutralization test (SN) with constant polyclonal serum and variable virus. This assay was carried out against BoHV-1, BoHV-5 and the recombinants in 96-well cell culture plates.

Sera against BoHV-1, BoHV-5 and the recombinant viruses were obtained from experimental infections assays in cattle, as previously reported (Ladelfa et al., 2011; Romera et al., 2014). Viruses were tenfold diluted, from $10^{-1}$ to $10^{-9}$ in Earlés Minimum Essential medium (E-MEM). Sera were mixed with the virus dilutions in an equal volume in a 96-well microtiter plate. After an incubation period of $2 \mathrm{~h}$ at $37^{\circ} \mathrm{C}$, the mixed volume was added to a MDBK cell monolayer. After a further incubation of $72 \mathrm{~h}$, endpoint virus titers were calculated using the Reed-Muench method.

Additionally, a VN assay using constant polyclonal serum m(Ab) anti gB- and the varying virus strains BoHV-1.1, 1.2a, 1.2b, 5a and 5b (recombinant isolates) was performed. As explained above, tenfold virus dilutions, from $10^{-1}$ to $10^{-9}$, were mixed with a 1:100 dilution of $\mathrm{m}(\mathrm{Ab})$ anti $\mathrm{gB}$, in a 96-well microtiter plate. After incubation at $37^{\circ} \mathrm{C}$, the $\mathrm{m}(\mathrm{Ab})$-virus mix was added to a MDBK cell monolayer. Endpoint neutralization virus titres were calculated as described above. For both assays, the neutralization index was calculated as the ratio between virus titer and virus neutralization titer, both with polyclonal serum and monoclonal antibody, respectively. 


\section{Results}

3.1. The differential clustering of $g B$ and $g D$ genes suggests that isolates A663, 166/84 and 674/10 are recombinant. Multiple PCR sequencing assays reveal the background of recombinant viruses to originate from BoHV5

Phylogenetic analyses demonstrate that the three isolates A663, $166 / 84$ and $674 / 10$, previously classified as BoHV-5 subtype b, cluster differently with BoHV-1 and BoHV-5 depending on the genes encoding glycoprotein $\mathrm{B}(\mathrm{gB})$ or $\mathrm{D}(\mathrm{gD})$, indicating these viruses are recombinants between BoHV-1 and BoHV-5 (Fig. 1).

To characterize the genomic background of the recombinants, we used eight PCR sequencing assays distributed along the whole genome. The amplified fragments displayed differences discriminating BoHV-1 from BoHV-5. Six fragments from genes localized within the unique long (UL) region (UL53, UL41, UL40, UL29, UL28, UL27 and UL22) and two from genes of the unique short (US) region (US6 and US8) were amplified. The alignment of genomic stretches allowed differentiation of the virus species at each selected locus. The resulting amplicons differed from sequences of BoHV-1 and BoHV-5 via several distinct point mutations, deletions, and insertions. The analysis of the loci and the observed divergences between the sequences allowed an accurate discrimination between BoHV-1 and BoHV-5.

\subsection{Two crossover points localized within the gB gene in the three recombinant viruses}

Based on the analyzed sequences, we located recombination sites within each of the recombinant viruses. We detected two possible crossover points, as evidenced during alignment with the parental strain by a disruption in the sequence. In 42 field isolates of BoHV-1, specific markers were identified $17 \mathrm{bp}$ upstream of the $5^{\prime}$ end of the UL27 gene. Downstream of this region, changes were only detected in isolates classified as BoHV5b. In view of this, we suggest that the recombination event occurred in the $18 \mathrm{bp}$ stretch at the $5^{\prime}$ region of the UL27 gene (nt 56019-556037, based on BoHV1 sequence, nt 56565-56583 based on BoHV-5). At the other crossover point (CO), the identification of a $14 \mathrm{bp}$ of homology downstream of BoHV1-specific markers allowed identification of the recombination site within the UL27 gene (nt 58269-58283 based on BoHV1, nt 58839-58853 based on BoHV-5). The two regions of homologies share common features (Fig. 2) in that both are relatively short (less than $45 \mathrm{bp}$ ) and both contain a stretch of 35 successive nucleotides with a high GC content (90\%). In light of these findings, we investigated the complete gene sequence in search of other recombination points.

The complete UL27 gene was amplified from the three virus isolates A663, 166/84 and 674/10 by PCR aand deposited in the GenBank (Accession numbers: KU992438, KU992439 and KU992440). Amplicons were cloned into pUC18 plasmids and sequenced in both $5^{\prime}$ and $3^{\prime}$ direction. The results were confirmed by Simplot analysis based on the complete UL27 gene.

Based on the sequence of the UL27 gene of BoHV5 (YP003662497.1), the first crossover point is extended from nt position 475 to 491 and the second crossover point is lies between positions 2749 to 2761 , resulting in a recombination fragment of $2286 \mathrm{bp}$. This fragment shows $100 \%$ identity to BoHV-1.2b (Fig. 2).

The total number of aa between the recombinant and parental strains differs somewhat. The aa sequences of the three recombinant gps (gB chimeric) are identical to those of the parental strains, except for a change shared by all three chimeras, where alanine is swapped for threonine at position 870 , and a second change only in chimera 166/84, where glutamic acid is replaced by alanine at position 667 .
3.3. Molecular modeling, construction, and structural model analysis of recombinant $\mathrm{gB}$ reveals a structural model of a parent-like chimeric glycoprotein

Structural models of $\mathrm{gB}$ of BoHV-1.1, BoHV-5 and the recombinant isolates 166/84, 674/10 and A6663 were made with Swiss Model (Arnold et al., 2006; Guex and Peitsch, 1997; Kiefer et al., 2009; Schwede et al., 2003), using the crystal structure of HSV-1 gB as template (pdb code: 3NW8, (Stampfer et al., 2010) HSV-1 vs BoHV-1 or BoHV $-5 \sim 50 \%$ identity). The structural models cover nearly $\sim 73 \%$ of the protein sequences (residues 121-763 in the chimera 166/84). The $\mathrm{N}$ terminal and $C$ terminal regions (residues 1-120 and 764-955 in the chimera 166/84, respectively) have no available structural template and seem to have large amounts of disorder as predicted by the program PONDR (Fig. S1) (Romero et al., 2001). The structural models obtained are all similar to each other (Fig. 3a), and also to previously reported BoHV-1 and BoHV-5 models (Levings and Roth, 2013). The only exception is a region of domain II, enriched in proline residues, which is absent in the template structure and had to be reconstructed (Fig3a). The sequence variability (residues485-525 in BoHV-1 gB, 492-539 in BoHV-5 gB, and 492-532 in the 166/84 gB chimera), lack of stable structure in the template and low quality value of this region in the models (Fig. S2), is due most probably to local conformational flexibility.

Fig. 4 shows the aa sequence alignment between the recombinant 166/84 gB chimera, the parental BoHV-1 and BoHV-5 gB, and HSV-1 $\mathrm{gB}$, used as template for the structural models. Similarities and differences between the chimeras and the parental sequences are highlighted. The central region of the chimera corresponds to BoHV-1 (residues $\sim 197-901, \sim 75 \%$ of the sequence), whereas the $\mathrm{N}$ terminal and $\mathrm{C}$ terminal regions (residues $\sim 1-196$ and $\sim 902-939$, respectively) correspond to BoHV-5 (21\% and $4 \%$ of the sequence, respectively). The central region encompass most parts of all domains of the glycoprotein, the N-terminal region contributes a small part of domains 1, 2, 3 and 4 and the $C$ terminal region encompass the last part of the cytoplasmic domain (Fig. 4). Residues identical to BoHV-1 or BoHV-5 gB in the recombinant chimeras are highlighted in Fig. 4 and also mapped in the structural model of the chimera 166/84 (Fig. 3b). This analysis shows that the domain loop II is enriched in residues that correspond to BoHV1. The prediction of linear epitopes for BoHV-1, BoHV-5 and the 166/84 chimera, was carried out using the program Bepipred (Larsen et al., 2006). Predicted epitopes were labeled on the aa protein sequences (Fig. 4) and mapped on the structural model of the 166/84 gB chimera (Fig. 3c).

\subsection{The in vitro characterization determined that although the genetic} background is similar to BoHV5, the recombinant viruses show cell-cell dispersion similar to BoHV1 indicating that $\mathrm{gB}$ would have a preponderant role in this function

The lysis plaque size assay represents an indirect measure of viral cell-to cell spread and a direct measure of viral lytic potential. During plaque size comparison of parental and recombinant strains, only showed statistically significant differences, plaques generated by one of the parental virus (BoHV5a) and one of the recombinant viruses (166/ 84) ( $p>0.005$ ) (Fig. 5a).The infection plaque assay considers both the cells lysed by the virus and also the infected cells expressing viral antigens on their surface, being a direct method to study cell-to-cell diffusion. Comparison between BoHV5a-generated infection plaques and recombinant strains showed significant differences $(\mathrm{p}>0.005)$, the largest plaques being generated by the major parental (06/ $13=$ BoHV5a) than those generated by all recombinant strains (Fig. 5b). 

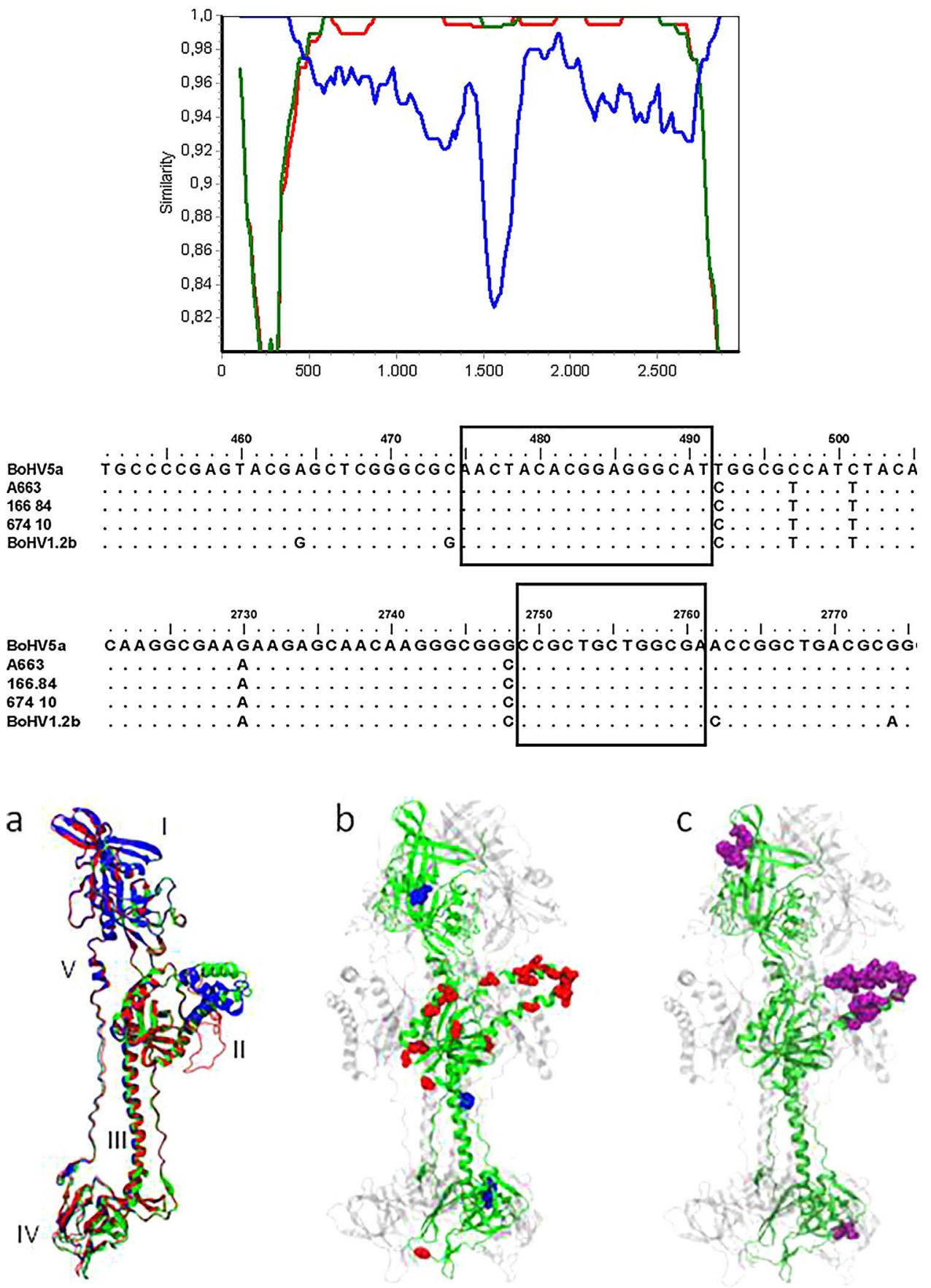

3.5. Recombinant viruses are recognized by bovine sera against different subtypes of BoHV-1 and BoHV-5 and also by a monoclonal antibody used in a BoHV-1 diagnostic kit

A serum neutralization assay using different polyclonal sera against each of the parental viruses and the recombinant viruses showed recognition at different degrees (Table 2). The VN assay with the parental virus and the recombinant isolates using the monoclonal antibody against gB (used in the Serelisa IBR/IPV gB Ab mono blocking kit) recognizes all recombinant viruses.

\section{Discussion}

Here, we provide the first evidence of natural interspecies recombination between two related ruminant alphaherpesviruses (BoHV-
Fig. 2. (A) Nucleotide identity plot of UL27 gene compared with BoHV1.2b and BoHV5a reference strains, the recombinant A663, 166/84 and 674/10 strains. Nucleotide positions are reported on the Xaxis and percent similarity on Y-axis. (B) Multiple alignment of sequence of UL27 in comparison to the corresponding sequences of BoHV1.2b, BoHV5a and recombinant viruses.
Fig. 3. a) Superposition of the structural models of gB from BoHV1 (red), BoHV5 (blue) and recombinant chimera 166/84 (green), obtained using the crystal structure of HSV1 (pdb: 3NW8) as template. b) Trimeric structural model of the recombinant 166/84 chimera. The residues are colored by their similarity to the BoHV1 and BoHV5 sequences. Residues identical to both BoHV1 and BoHV5 are colored green. Residues only identical to BoHV1 are represented as red VDW spheres, and those only identical to BoHV-5 are represented as blue VDW spheres. c) Analysis of the 166/84 chimera with the program Bepipred. The linear epitopes predicted with the program are represented as purple VDW spheres on chain A (green) of the trimeric structural model of the chimera. (For interpretation of the references to colour in this figure legend, the reader is referred to the web version of this article.)
1 and BoHV-5), at a reduced degree of genomic similarity $(82.3 \%$ average similarity). Based on phylogenetic analysis, multiple PCR sequencing assays and sequence and genetic recombination analysis using a sliding-window genetic diversity plot (Simplot), we found three recombinant field isolates between BoHV-1 and BoHV-5. Our findings indicate that BoHV-5 subtype b, whose current classification by REA is based on the analysis of the three examined field isolates, should rather be considered as a natural recombinant of BoHV-5 subtype a and BoHV1 subtype $1.2 \mathrm{~b}$. The recombination event causes the disappearance of a restriction site for enzyme BstEII, generating a typical restriction pattern responsible for the classification as BoHV-5 subtype "b".

We identified and sequenced two homologous recombination sites in three field isolates. Concurring with our previous observations (Del Medico Zajac et al., 2009), these new findings contrast with the currently proposed double-strand break repair model for homologous 
gB HSV1

gB_BOHVI

gB BOHV5

gB_Rec166/84

gB HSV1

gB_HSV1

gB_BOHV1

gB Rec166/8

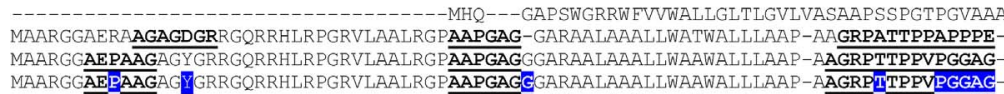
II RPAG

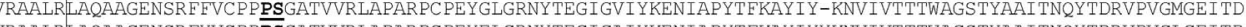
RPADGDDGDDDNGTDVRALR AQA

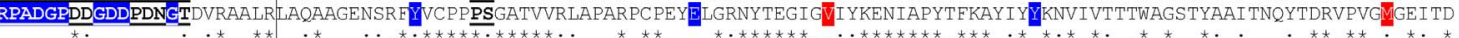

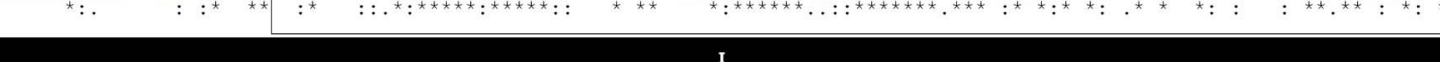

KINAKGVCRSTAKYVRNNLETTAFHRDDHETDMELKPANAATRTSRGWHTTDLKYNPSRVEAFHRYGTTVNCIVEEVDARSVYPYDE EVLATGDEVYMSPFYGYREGSHTEHTSYAADRF LVDKKWRCLSKAEYLRSGRKVVAFDRDDDPWEAPLKPARLSAPGVRGWHTTDDVYTALGSAGLYRTGTSVINCIVEEVEARSVYPYDSEALSTGDI I YMSPFYGLREGAHREHTSYSPERF LVDKKWRCLSKAEYLRSGRKVVAFDRDEDPWEAPLKPARLSAPGVRGWHTTDEVYTALGSAGLYRTGTSVICIVEEVEARSVYPYDSEALSTGDI IYMSPFYGLRDGAHREHTSYSPERF

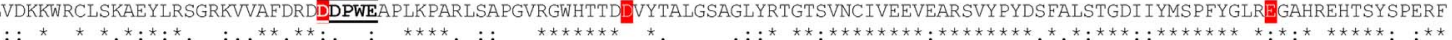

\begin{tabular}{l|l} 
I & II
\end{tabular}

KQVDG FYRDT

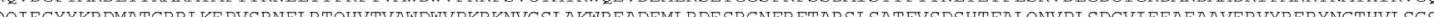
QO QQIEG YTKRDMATR

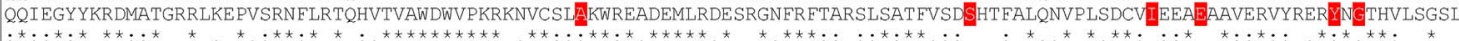

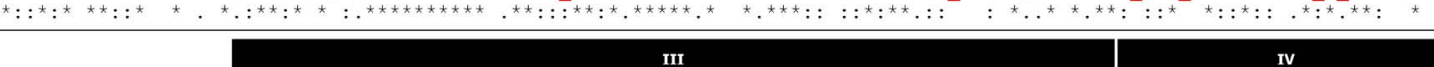

gB_HSV1

gB-BOHV1

gB Rec166/84

\section{QYYLANGGELIAYQPLISNTLAELYVREHLREQS} ETYLARGGFVVAFRPMLSNELAKLYLQELARSNGTLEGLFAA TYLARGGFVVAFRPMLSNALAKLYLQELARSNGTLEGLFAAGGSGAAAAAA PKPVPRRARRSASPTPPAP-AASGDGGDGDANKRVTTVSSAEFAALQFTYDHIQDHVNTMFSRLATSW TYLARGGEVVAFRMLSN LAKLYLQELARSNGILEGLFAA----AAPKPGPRRARRAAPSAPGEPEAANGEAGDGDAGGRVTVSSAEEAALQETYDHIQDHVNTMFSR LATSW

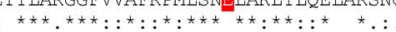

IV

III

\section{${ }^{\star}: *^{*} \cdot{ }^{* *}{ }^{* \star *}$}

gB_HSV1

gB_BOHV1

gB_Rec166/84

CELONHELTLWNEARKLNPNAIASVTVGRRVSARMLGDVMAVSTCVPVARDNVIVONSMRISSRPGACYSRPLVSERYEDOGPLVEGOLGENNELRLTRDAIEPCTVGHRRYFTFGGGYV CLLQNKERALWAEAAKLNP SAAASAALDRRAAARMLGDAMAVTYCHELGEGRVF I ENSMRA--PGGVCYSRP PVSFAFGNESEPVEGQLGEDNELIPGRELVEPCTANHKRY FRFGADYV CLIQNKERALWAEAAKLNP SAAASAALDRRAAARMLGDAMAVTYCHE LGEGRVF IENSMRA--PGGVCYSRP PVSEAFGNESEPVEGQLGEDNELIPGRELVEPCTANHKRYFRFGADY CLLQNKERALWAEAAKLNP SAAASAALDRRAAARMLGDAMAVTYCHELGEGRVFIENSMRA--PGGVCYSRPPVSEAFGNESEPVEGQLGEDNELIPGRELVEPCALNHKRYFRFGADYV

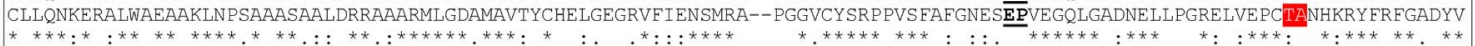

\section{MPR}

TM

\section{CD}

gB_HSV1

gB_BOHV1

gB Rec166/84

YFEEYAYSHQLSRADI TTVSTFI DLNI TMLE DHE FVPLEVYTRHE I KDSGLLDYTEVQRRNQLHDLRFADIDTVI HADANAAMFAGLGAFFEGMGDLGRAVGKVVMGIVGGVVSAVSGVS YYENYAYVRRVPLAE LEVI ST FVDLNLTVLEDREFLPLEVYTRAE LADTGLLDYSEIQRRNQLHEIRFYDI DRVVKTDGNMAIMRGLANEFOGLGAVGQAVGTVVLGAAGAALSTVSGIA YYENYAYVRRVPLAE LEVISTFVDLNLTVLEDREFLPLEVYTRAELADTGLLDYSEIORRNQLHELRFYDIDRVVKTDGNMAIMRGLANFFQGLGAVGQAVGTVVLGAAGAALSTVSGTA YYENYAYVRRVPLAE LEVIST FVDLNLTVLEDREFLPLEVYTRAE LADTGLLDYSEIQRRNQLHELRFYDIDRVVKTDGNMAIMRGLANEFQGLGAVGQAVGTVVLGAAGAALSTVSGIA

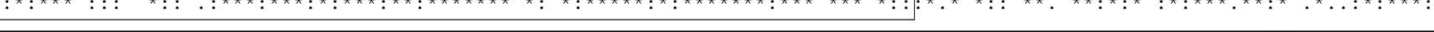

gB_HSV1

gB BoHV1

gB_BOHV5

gB_Rec166/84

CD

$\square$

SFMSNPFGALAVGLLVLAGLAAAFEAFRYVMRLQSNPMKALYPLTTKELKNPTNPDASGEGEEGGDFDEAKLAEAREMIRYMALVSAMERTEHKAKKKGTS-ALLSAKVTDMVMRKRRN SFIANPFGALATGLLVLAGLVAAFLAYRYISRLRSNPMKALYPITTRALKDDARGATAPGEE-EEEFDAAKLEQAREMIKYMSLVSAVEROEHKAKKSNKGGPLIAATRLTOLALRRRAPP

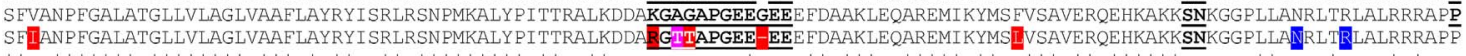

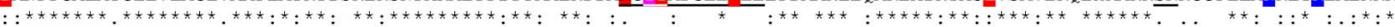
CD

gB_HSV1

gB_BOHV1

gB BOHV5

gB Rec166/84

NYTQVPNKDGDADEDDI

AYQQLPMSDVGEP---

AYQQLPMSDVG

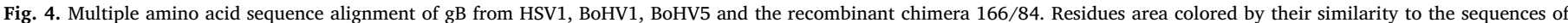

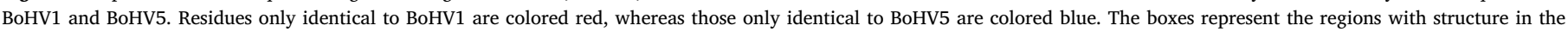

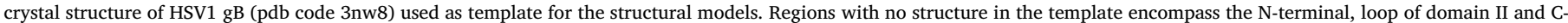

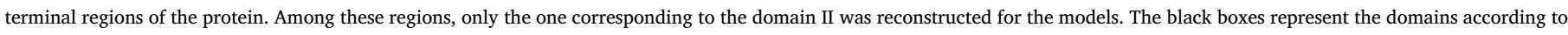

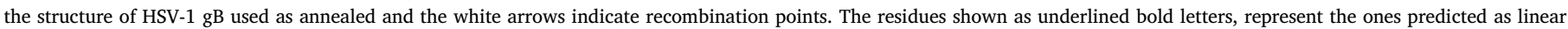
epitopes with the Bepipred program. (For interpretation of the references to colour in this figure legend, the reader is referred to the web version of this article.)

A

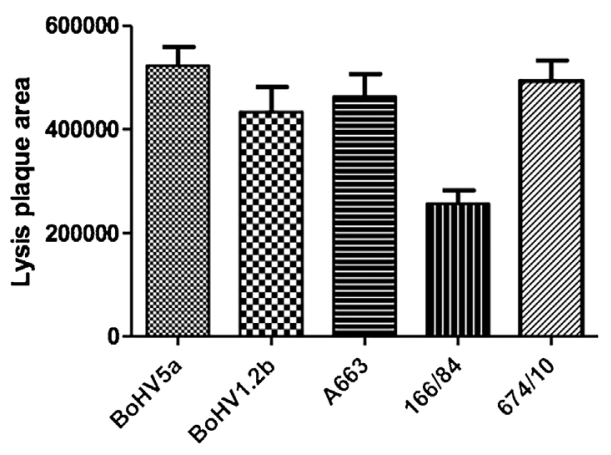

B

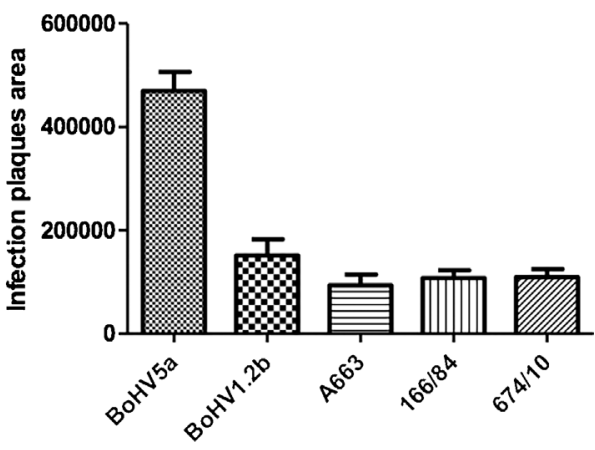

Fig. 5. In vitro characterization. A: Lysis plaque generated by recombinant and parental strains. Error bars represent standard deviation. BoHV5a and 166/ 84 is significantly different (Tukey test, $\mathrm{P}<0.05$ ). B: Infection plaque generated by recombinant and parental strains. Error bars represent standard deviation. BoHV5a and all recombinant strains are significantly different (Tukey test, $\mathrm{P}<0.05$ ). 
Table 2

Specific and non-specific reactions of recombinant viruses in SN assays by four BoHV1/5elicited bovine polyclonal sera and one commercial monoclonal antibody.

\begin{tabular}{|c|c|c|c|c|c|c|}
\hline & & \multicolumn{2}{|l|}{ BoHV1 } & \multirow{2}{*}{$\begin{array}{l}\text { BoHV5 } \\
\text { N569 }\end{array}$} & \multirow{2}{*}{$\begin{array}{l}\text { BoHV5 } \\
\text { recom. }\end{array}$} & \multirow{2}{*}{$\begin{array}{l}\text { No virus } \\
\text { CC }\end{array}$} \\
\hline & & LA & K22 & & & \\
\hline \multirow[t]{5}{*}{ Polyclonal sera } & a-BoHV1.1 & +++ & ++ & +++ & $-1+$ & - \\
\hline & $\alpha$-BoHV1.2b & ++ & +++ & ++ & ++ & - \\
\hline & $\alpha$-BoHV5a & ++ & ++ & +++ & ++ & - \\
\hline & $\begin{array}{l}\alpha \text {-BoHV5 } \\
\text { recom. }\end{array}$ & ++ & ++ & ++ & ++ & - \\
\hline & $\begin{array}{l}\text { Mab. A-gB } \\
\text { (Commercial } \\
\text { kit) }\end{array}$ & +++ & ++ & +++ & ++ & - \\
\hline
\end{tabular}

Intensity of the recognition: - negative; $+/$ - very weak/questionable; ++ moderate $(1$ $\log ) ;+++$ strong.

herpesvirus recombination (Thiry et al., 2005; Umene, 1999), as the region of homology detected in the two recombination sites is two times smaller than the minimal region shown to be actively involved in the synapsis formed during RecA-mediated homologous recombination (van der Heijden et al., 2008). Our previous report (Del Medico Zajac et al., 2011) showed that recombination occurred within small fragments of perfect sequence homology where only 38 and $44 \mathrm{bp}$ of homology were detected in both recombination sites. In this work, natural recombination also occurred within a short fragment of homology of 14 to $18 \mathrm{bp}$ detected around both recombination sites (Fig. 2). Furthermore, our results support the postulate by (Meurens et al., 2004) stating that the occurrence of a first recombination event positively influences the occurrence of a second recombination event in a neighboring region. To explain the generation of these recombinant viruses, two hypotheses could be put forth; either both recombination points originated in a single recombination event or resulted from a double recombination event in simple recombinant genomes.

Since both recombination events were located within the chimeric gB sequence (encoded by $80 \%$ of the BoHV- 1 and $20 \%$ of the BoHV- 5 sequence), the conserved transmembrane $\mathrm{gB}$ glycoprotein was further investigated by molecular modeling.

Levings et al. (2015) report that, based on the crystal structures of HSV1 (3NW8), BoHV-1 and BoHV-5 gB structures are similar. Here we show that models of chimeric $\mathrm{gB}$ of recombinant viruses are similar to $\mathrm{gB}$ parental structures. In the chimera, we observed the same domain construct as characterized for HSV-1 gB (Heldwein et al., 2006). In addition, chimeric $\mathrm{gB}$ shows a combination of linear epitopes of parental $\mathrm{gBs}$, while not possessing own linear epitopes. Based on these studies, we can conclude that the recombination events did not affect the three-dimensional structure of the glycoprotein of the recombinant viruses, and can further infer that vital functions attributed to the glycoprotein were not affected. However, the in vitro characterization performed here suggests that all recombinant strains possess decreased capacities for cell-to-cell spread compared to the parental strain (BoHV5a) but not to the other parental virus (BoHV1.2b) indicating that perhaps in this biological characteristic the recombinant viruses behave similarly to the BoHV1. These results should be further elucidated once the complete genetic background of the recombinant strains is analyzed since the possibility of other recombination points with an impact on in vitro and in vivo behavior of these viruses cannot be ruled out.

In this study, the immunogenicity of these recombinant viruses was investigated via serum neutralization. Polyclonal sera reacted against the different virus species and their subtypes, supporting the widely proposed hypothesis of cross-neutralization between different ruminant alphaherpesviruses. In view of the observed differences in the degree of neutralization for the recombinant viruses and their failure in escaping the classical serological test for ruminant alphaherpesviruses, it is possible that they cannot however entirely escape immunity induced by vaccines or outbreaks of BoHV-1.

In South American countries, especially Brazil and Argentina, where BoHV-1 and BoHV-5 co-circulate and vaccination is not obligatory (Del Medico Zajac et al., 2009; Maidana et al., 2014, 2013), cattle can easily be co-infected with different virus species. Subsequent interspecies recombination can then occur, generating recombinant viruses with unknown biological characteristics. In our study, three BoHV strains, previously classified as BoHV-5 subtype b, have been retrospectively identified as recombinants. Two of these were isolated in the early 80 's during an outbreak of typical nervous BoHV-5 involving calf death. The third was isolated in 2010 from the semen of an asymptomatic adult bull, indicating that the recombinant viruses can successfully spread and be maintained within the cattle population. The latter observation is in apparent contrast to the initial attenuation observed for in vitrogenerated recombinant BoHV-1/5 viruses (Del Medico Zajac et al., 2011). While it is unsurprising that a recombination event may initially attenuate a novel chimeric strain (genome instabilities may ensue), it appears that this does not necessarily exclude its circulation in vivo. We could postulate that a less virulent, recombinant BoHVs might pose less of a threat to the immune system and evade recognition, immune control and elimination allowing persistence in a latent state and circulation in the ruminant population at low quantities.

The detection of natural recombination in alphaherpesviruses varies from limited or absent in FeHV-1 and equid herpesvirus 1 (EHV-1) (Vaz et al., 2016a; Vaz et al., 2016b) to widespread in HSV-1, EHV-4 and gallid herpesvirus 1 (GaHV-1) (Kolb et al., 2015; Lee et al., 2013; Lee et al., 2012; Szpara et al., 2014; Vaz et al., 2016a) suggesting that the contribution that recombination makes to genomic diversification and evolution in alphaherpesviruses varies across the different virus species (Loncoman et al., 2017).

Amongst ruminant alphaherpesviruses, homologous recombination has been shown to occur between viruses with high (BoHV-1 subtypes) (Muylkens et al., 2009; Schynts et al., 2003) as well as low genomic similarity (BoHV-1 and 5) (Meurens et al., 2004; and data reported here. The generation of novel recombinant viruses between ruminant alphaherpesviruses may also occur in regions, where, in new mixed production systems, two or more ruminant species coexist, presenting conducive environments for viral co-circulation. In Argentina, these conditions are fulfilled in the northwestern and southern regions where different species of ruminants share the same habitat. From the generation of natural recombinants of co-circulating strains as shown here, potential risks of recombination between circulating strains may be extrapolated.

In conclusion, we identify recombinant ruminant alphaherpesviruses and provide evidence of the existence of natural recombinants and recombination events within distinct viral species in the subfamily Alphaherpesvirinae. Special attention should be paid to natural recombination between bovine herpesvirus strains as it can potentially increase the complexity of differential diagnosis and unknown pathogenesis of BoHV-1 infections, augment the risk of vaccineinduced immunity escape and lead to the generation of vaccine-strain recombinants. This highlights the importance of combining studies that examine recombination in experimental settings with those that investigate recombination in field isolates from naturally infected hosts. It is clear that further examination of natural recombination in bovine alphaherpesviruses at a population level is merited.

\section{Acknowledgements}

The authors wish to thank Lorène Dams for her excellent technical assistance (University of Liege, Belgium). This study was financially supported by the Agencia Nacional de Promoción Científica y Tecnológica (ANPyCT), Ministerio de Ciencia, Tecnología e InnovaciónProductiva, Argentina (BID-PICT $\mathrm{N}^{\circ} 1460$ ); INTA (PNSA 1115054 and 1115055) and FNRS-CONICET (Res. $N^{\circ} 3334 / 14$ ) 


\section{Appendix A. Supplementary data}

Supplementary data associated with this article can be found, in the online version, at http://dx.doi.org/10.1016/j.virusres.2017.09.018.

\section{References}

Arnold, K., Bordoli, L., Kopp, J., Schwede, T., 2006. The SWISS-MODEL workspace: a web-based environment for protein structure homology modelling. Bioinformatics 22, 195-201. http://dx.doi.org/10.1093/bioinformatics/bti770.

Benkert, P., Biasini, M., Schwede, T., 2011. Toward the estimation of the absolute quality of individual protein structure models. Bioinformatics 27, 343-350. http://dx.doi. org/10.1093/bioinformatics/btq662.

Brown, S.M., Subak-Sharpe, J.H., Harland, J., MacLean, A.R., 1992. Analysis of intrastrain recombination in herpes simplex virus type 1 strain 17 and herpes simplex virus type 2 strain HG52 using restriction endonuclease sites as unselected markers and temperature-sensitive lesions as selected markers. J. Gen. Virol. 73 (Pt 2), 293-301. http://dx.doi.org/10.1099/0022-1317-73-2-293.

d'Offay, J.M., Mock, R.E., Fulton, R.W., 1993. Isolation and characterization of encephalitic bovine herpesvirus type 1 isolates from cattle in North America. AM. J. Vet. Res . 54, 534-539.

Dangler, C.A., Henderson, L.M., Bowman, L.A., Deaver, R.E., 1993. Direct isolation and identification of recombinant pseudorabies virus strains from tissues of experimentally co-infected swine. Am. J. Vet. Res. 54, 540-545.

Delhon, G., Moraes, M.P., Lu, Z., Afonso, C.L., Flores, E.F., Weiblen, R., Kutish, G.F., Rock, D.L., 2003. Genome of bovine herpesvirus 5. J. Virol . 77, 10339-10347.

Del Medico Zajac, M.P., Romera, S.A., Ladelfa, M.F., Kotsias, F., Thiry, J., Ziant, D., Meurens, F., Keil, G.M., Thiry, E., Muylkens, B., 2009. Characterization of interspecific recombinants generated from closely related bovine herpesviruses 1 and 5 through multiple PCR sequencing assays. J. Virol. Methods 161, 75-83. http://dx. doi.org/10.1016/j.jviromet.2009.05.020.

Del Medico Zajac, M.P., Ladelfa, M.F., Kotsias, F., Muylkens, B., Thiry, J., Thiry, E., Romera, S.A., 2010. Biology of bovine herpesvirus 5. Vet. J. 184, 138-145. http://dx. doi.org/10.1016/j.tvjl.2009.03.035.

Del Medico Zajac, M.P., Romera, S.A., Ladelfa, M.F., Kotsias, F., Delgado, F., Thiry, J., Meurens, F., Keil, G., Thiry, E., Muylkens, B., 2011. In vitro-generated interspecific recombinants between bovine herpesviruses 1 and 5 show attenuated replication characteristics and establish latency in the natural host. BMC Vet. Res. 7, 19. http:// dx.doi.org/10.1186/1746-6148-7-19.

Dohner, D.E., Adams, S.G., Gelb, L.D., 1988. Recombination in tissue culture between varicella-zoster virus strains. J. Med. Virol. 24, 329-341.

Fujita, K., Maeda, K., Yokoyama, N., Miyazawa, T., Kai, C., Mikami, T., 1998. In vitro recombination of feline herpesvirus type 1. Arch. Virol. 143, 25-34.

Glazenburg, K.L., Moormann, R.J., Kimman, T.G., Gielkens, A.L., Peeters, B.P., 1994. In vivo recombination of pseudorabies virus strains in mice. Virus Res. 34, 115-126.

Guex, N., Peitsch, M.C., 1997. SWISS-MODEL and the Swiss-PdbViewer: an environment for comparative protein modeling. Electrophoresis 18, 2714-2723. http://dx.doi. org/10.1002/elps.1150181505.

Heldwein, E.E., Lou, H., Bender, F.C., Cohen, G.H., Eisenberg, R.J., Harrison, S.C., 2006. Crystal structure of glycoprotein B from herpes simplex virus 1 . Science 313 , 217-220. http://dx.doi.org/10.1126/science.1126548.

Henderson, L.M., Katz, J.B., Erickson, G.A., Mayfield, J.E., 1990. In vivo and in vitro genetic recombination between conventional and gene-deleted vaccine strains of pseudorabies virus. Am. J. Vet. Res. 51, 1656-1662.

Hughes, A.L., Rivailler, P., 2007. Phylogeny and recombination history of gallid herpesvirus 2 (Marek's disease virus) genomes. Virus Res. 130, 28-33. http://dx.doi.org/ 10.1016/j.virusres.2007.05.008.

Kiefer, F., Arnold, K., Künzli, M., Bordoli, L., Schwede, T., 2009. The SWISS-MODEL repository and associated resources. Nucleic Acids Res. 37, D387-92. http://dx.doi. org/10.1093/nar/gkn750.

Kolb, A.W., Larsen, I.V., Cuellar, J.A., Brandt, C.R., 2015. Genomic, phylogenetic, and recombinational characterization of herpes simplex virus 2 strains. J. Virol. 89, 6427-6434. http://dx.doi.org/10.1128/JVI.00416-15.

Larsen, J., Lund, O., Nielsen, M., 2006. Improved method for predicting linear B-cell epitopes. Immunome Res. 2, 2. http://dx.doi.org/10.1186/1745-7580-2-2.

Ladelfa, M.F., Del Médico Zajac, M.P., Kotsias, F., Delgado, F., Muylkens, B., Thiry, J., Thiry, E., Romera, S.A., 2011. Comparative study on the in vitro and in vivo properties of two bovine herpesvirus-5 reference strains. Acta Vet Scand. 53, 37. http:// dx.doi.org/10.1186/1751-0147-53-37.

Lee, S.-W., Devlin, J.M., Markham, J.F., Noormohammadi, A.H., Browning, G.F., Ficorilli, N.P., Hartley, C.A., Markham, P.F., 2011. Comparative analysis of the complete genome sequences of two Australian origin live attenuated vaccines of infectious laryngotracheitis virus. Vaccine 29, 9583-9587. http://dx.doi.org/10.1016/j. vaccine.2011.10.055.

Lee, K., Kolb, A.W., Sverchkov, Y., Cuellar, J.A., Craven, M., Brandt, C.R., 2015. Recombination Analysis of Herpes Simplex Virus 1 Reveals a Bias toward GC Content and the Inverted Repeat Regions. J. Virol . 89, 7214-7223. http://dx.doi.org/10. 1128/JVI.00880-15.

Levings, R.L., Roth, J.A., 2013. Immunity to bovine herpesvirus 1: I. Viral lifecycle and innate immunity. Anim. Health Res. Rev. 14. http://dx.doi.org/10.1017/ S1466252313000042.

Levings, R.L., Collins, J.K., Patterson, P.A., Roth, J.A., 2015. Virus, strain, and epitope specificities of neutralizing bovine monoclonal antibodies to bovine herpesvirus 1 glycoproteins $\mathrm{gB}, \mathrm{gC}$, and $\mathrm{gD}$, with sequence and molecular model analysis. Vet.
Immunol. Immunopathol. 164, 179-193. http://dx.doi.org/10.1016/j.vetimm.2015. 02.009 .

Loncoman, C.A., Vaz, P.K., Coppo, M.J., Hartley, C.A., Morera, F.J., Browning, G.F., Devlin, J.M., 2017. Natural recombination in alphaherpesviruses: insights into viral evolution through full genome sequencing and sequence analysis. Infect. Genet. Evol. 49, 174-185. http://dx.doi.org/10.1016/j.meegid.2016.12.022.

Maidana, S.S., Ladelfa, M.F., Pérez, S.E., Lomónaco, P.M., Del Médico Zajac, M.P., Odeón, A., Blanco Viera, J., Combessies, G., Fondevila, N., Palacios, M., Thiry, J., Muylkens, B., Thiry, E., Romera, S.A., 2011. Characterization of BoHV-5 field strains circulation and report of transient specific subtype of bovine herpesvirus 5 in Argentina. BMC Vet. Res . 7 (8).

Maidana, S.S., Morano, C.D., Cianfrini, D., Campos, F.S., Roehe, P.M., Siedler, B., De Stefano, G., Mauroy, A., Thiry, E., Romera, S.A., 2013. Multiplex PCR followed by restriction length polymorphism analysis for the subtyping of bovine herpesvirus 5 isolates. BMC Vet. Res. 9, 111. http://dx.doi.org/10.1186/1746-6148-9-111.

Maidana, S.S., Konrad, J.L., Craig, M.I., Zabal, O., Mauroy, A., Thiry, E., Crudeli, G., Romera, S.A., 2014. First report of isolation and molecular characterization of bubaline herpesvirus 1 (BuHV1) from Argentinean water buffaloes. Arch. Virol. 159, 2917-2923. http://dx.doi.org/10.1007/s00705-014-2146-8.

Martin, D.P., Murrell, B., Golden, M., Khoosal, A., Muhire, B., 2015. RDP4: Detection and analysis of recombination patterns in virus genomes. Virus Evol 1. http://dx.doi.org/ 10.1093/ve/vev003.

McGeoch, D.J., Dolan, A., Ralph, A.C., 2000. Toward a comprehensive phylogeny for mammalian and avian herpesviruses. J. Virol. 74, 10401-10406.

Meurens, F., Keil, G.M., Muylkens, B., Gogev, S., Schynts, F., Negro, S., Wiggers, L., Thiry, E., 2004. Interspecific recombination between two ruminant alphaherpesviruses, bovine herpesviruses 1 and 5. J. Virol. 78, 9828-9836. http://dx.doi.org/10.1128/ JVI.78.18.9828-9836.2004.

Muylkens, B., Meurens, F., Schynts, F., Farnir, F., Pourchet, A., Bardiau, M., Gogev, S., Thiry, J., Cuisenaire, A., Vanderplasschen, A., Thiry, E., Thiry, E., 2006. Intraspecific bovine herpesvirus 1 recombinants carrying glycoprotein $\mathrm{E}$ deletion as a vaccine marker are virulent in cattle. J. Gen. Virol. 87, 2149-2154. http://dx.doi.org/10. 1099/vir.0.81969-0.

Muylkens, B., Farnir, F., Meurens, F., Schynts, F., Vanderplasschen, A., Georges, M., Thiry, E., 2009. Coinfection with two closely related alphaherpesviruses results in a highly diversified recombination mosaic displaying negative genetic interference. J. Virol. 83, 3127-3137. http://dx.doi.org/10.1128/JVI.02474-08.

Nishiyama, Y., Kimura, H., Daikoku, T., 1991. Complementary lethal invasion of the central nervous system by nonneuroinvasive herpes simplex virus types 1 and 2 . J. Virol. 65, 4520-4524.

Norberg, P., Bergström, T., Rekabdar, E., Lindh, M., Liljeqvist, J.-A., 2004. Phylogenetic analysis of clinical herpes simplex virus type 1 isolates identified three genetic groups and recombinant viruses. J. Virol. 78, 10755-10764. http://dx.doi.org/10.1128/JVI. 78.19.10755-10764.2004.

Norberg, P., Liljeqvist, J.-A., Bergström, T., Sammons, S., Schmid, D.S., Loparev, V.N., 2006. Complete-genome phylogenetic approach to varicella-zoster virus evolution: genetic divergence and evidence for recombination. J. Virol. 80, 9569-9576. http:// dx.doi.org/10.1128/JVI.00835-06.

Norberg, P., Kasubi, M.J., Haarr, L., Bergstrom, T., Liljeqvist, J.-A., 2007. Divergence and recombination of clinical herpes simplex virus type 2 isolates. J. Virol. 81, 13158-13167. http://dx.doi.org/10.1128/JVI.01310-07.

Pagamjav, O., Sakata, T., Matsumura, T., Yamaguchi, T., Fukushi, H., 2005. Natural recombinant between equine herpesviruses 1 and 4 in the ICP4 gene. Microbiol. Immunol. 49, 167-179.

Peters, G.A., Tyler, S.D., Grose, C., Severini, A., Gray, M.J., Upton, C., Tipples, G.A., 2006 A full-genome phylogenetic analysis of varicella-zoster virus reveals a novel origin of replication-based genotyping scheme and evidence of recombination between major circulating clades. J. Virol. 80, 9850-9860. http://dx.doi.org/10.1128/JVI. 00715-06.

Raaperi, K., Orro, T., Viltrop, A., 2014. Epidemiology and control of bovine herpesvirus 1 infection in Europe. Vet. J. 201, 249-256. http://dx.doi.org/10.1016/j.tvjl.2014.05. 040 .

Rijsewijk, F.A., Verschuren, S.B., Madić, J., Ruuls, R.C., Renaud, P., van Oirschot, J.T., 1999. Spontaneous BHV1 recombinants in which the $\mathrm{gI} / \mathrm{gE} / \mathrm{US} 9$ region is replaced by a duplication/inversion of the US1.5/US2 region. Arch. Virol. 144, 1527-1537.

Romera, S.A., Hilgers, L.A., Puntel, M., Zamorano, P.I., Alcon, V.L., Dus Santos, M.J., Blanco Viera, J., Borca, M.V., Sadir, A.M., 2000. Adjuvant effects of sulfolipo-cyclodextrin in a squalane-in-water and water-in-mineral oil emulsions for BHV-1 vaccines in cattle. Vaccine 19, 132-141.

Romera, S.A., Puntel, M., Quattrocchi, V., Del Médico Zajac, P., Zamorano, P., Blanco Viera, J., Carrillo, C., Chowdhury, S., Borca V, M., Sadir, A.M., 2014. Protection induced by a glycoprotein E-deleted bovine herpesvirus type 1 marker strain used either as an inactivated or live attenuated vaccine in cattle. BMC. Vet. Res. 10, 8 http://dx.doi.org/10.1186/1746-6148-10-8.

Romero, P., Obradovic, Z., Li, X., Garner, E.C., Brown, C.J., Dunker, A.K., 2001. Sequence complexity of disordered protein. Proteins 42, 38-48.

Sakaoka, H., Kurita, K., Iida, Y., Takada, S., Umene, K., Kim, Y.T., Ren, C.S., Nahmias, A.J., 1994. Quantitative analysis of genomic polymorphism of herpes simplex virus type 1 strains from six countries: studies of molecular evolution and molecular epidemiology of the virus. J. Gen. Virol. 75, 513-527. http://dx.doi.org/10.1099/0022 1317-75-3-513.

Schwede, T., Kopp, J., Guex, N., Peitsch, M.C., 2003. SWISS-MODEL: An automated protein homology-modeling server. Nucleic Acids Res. 31, 3381-3385.

Schynts, F., Vanderplasschen, A., Hanon, E., Rijsewijk, F.A., van Oirschot, J.T., Thiry, E., 2001. Use of PCR and immunofluorescence to detect bovine herpesvirus 1 recombinants. J. Virol. Methods 92, 99-104. 
Schynts, F., Meurens, F., Detry, B., Vanderplasschen, A., Thiry, E., 2003. Rise and survival of bovine herpesvirus 1 recombinants after primary infection and reactivation from latency. J. Virol. 77, 12535-12542.

Shackelton, L.A., Holmes, E.C., 2004. The evolution of large DNA viruses: combining genomic information of viruses and their hosts. Trends Microbiol. 12, 458-465. http://dx.doi.org/10.1016/j.tim.2004.08.005.

Stampfer, S.D., Lou, H., Cohen, G.H., Eisenberg, R.J., Heldwein, E.E., 2010. Structural basis of local, $\mathrm{pH}$-dependent conformational changes in glycoprotein B from herpes simplex virus type 1. J. Virol. 84, 12924-12933. http://dx.doi.org/10.1128/JVI. 01750-10.

Szpara, M.L., Gatherer, D., Ochoa, A., Greenbaum, B., Dolan, A., Bowden, R.J., Enquist, L.W., Legendre, M., Davison, A.J., 2014. Evolution and diversity in human herpes simplex virus genomes. J. Virol. 88, 1209-1227. http://dx.doi.org/10.1128/JVI. 01987-13.

Tamura, K., Peterson, D., Peterson, N., Stecher, G., Nei, M., Kumar, S., 2011. MEGA5: Molecular Evolutionary Genetics Analysis Using Maximum Likelihood, Evolutionary Distance, and Maximum Parsimony Methods. Mol. Biol. 28, 2731-2739. http://dx. doi.org/10.1093/molbev/msr121. Evol.

Thiry, E., Meurens, F., Muylkens, B., McVoy, M., Gogev, S., Thiry, J., Vanderplasschen, A., Epstein, A., Keil, G., Schynts, F., 2005. Recombination in alphaherpesviruses. Rev. Med. Virol. 15, 89-103. http://dx.doi.org/10.1002/rmv.451.

Thiry, E., Muylkens, B., Meurens, F., Gogev, S., Thiry, J., Vanderplasschen, A., Schynts, F.,
2006. Recombination in the alphaherpesvirus bovine herpesvirus 1. J. Virol . 73, $152-160$.

Thiry, J., Widén, F., Grégoire, F., Linden, A., Belák, S., Thiry, E., 2007. Isolation and characterisation of a ruminant alphaherpesvirus closely related to bovine herpesvirus 1 in a free-ranging red deer. BMC Vet. Res. http://dx.doi.org/10.1186/1746-61483-26.

Umene, K., 1999. Mechanism and application of genetic recombination in herpesviruses Rev. Med. Virol. 9, 171-182.

van Drunen Littel-van den Hurk, S., 2007. Cell-mediated immune responses induced by BHV-1: rational vaccine design. Expert Rev. Vaccines 6, 369-380. http://dx.doi.org/ 10.1586/14760584.6.3.369.

van der Heijden, T., Modesti, M., Hage, S., Kanaar, R., Wyman, C., Dekker, C., 2008. Homologous recombination in real time: DNA strand exchange by RecA. Mol. Cell 30, 530-538. http://dx.doi.org/10.1016/j.molcel.2008.03.010.

Vaz, P.K., Job, N., Horsington, J., Ficorilli, N., Studdert, M.J., Hartley, C.A., Gilkerson, J.R., Browning, G.F., Devlin, J.M., 2016a. Low genetic diversity among historical and contemporary clinical isolates of felid herpesvirus 1 . BMC Genomics 17, 704. http:// dx.doi.org/10.1186/s12864-016-3050-2.

Vaz, P.K., Horsington, J., Hartley, C.A., Browning, G.F., Ficorilli, N.P., Studdert, M.J., Gilkerson, J.R., Devlin, J.M., 2017b. Evidence of widespread natural recombination among field isolates of equine herpesvirus 4 but not among field isolates of equine herpesvirus 1. J. Gen. Virol . 97, 747-755. http://dx.doi.org/10.1099/jgv.0.000378. 